\title{
Precocious puberty: a clinical review
}

\author{
Pallavee P.*, Rupal Samal
}

Department of Obstetrics and Gynecology, Mahatma Gandhi Medical College and Research Institute, Pondicherry, India

Received: 19 December 2017

Accepted: 20 January 2018

\section{*Correspondence:}

Dr. Pallavee P.,

E-mail: ppallavee@ rediffmail.com

Copyright: () the author(s), publisher and licensee Medip Academy. This is an open-access article distributed under the terms of the Creative Commons Attribution Non-Commercial License, which permits unrestricted non-commercial use, distribution, and reproduction in any medium, provided the original work is properly cited.

\begin{abstract}
Precocious puberty is defined as pubertal development occurring more than 2.5 standard deviations earlier than the average age. It may comprise of central or gonadotropin-dependent precocious puberty and peripheral or gonadotropin-independent precocious puberty. Variants of precocious puberty include premature thelarche, premature pubarche and isolated premature menarche which principally implies onset of menstruation without any other signs of sexual development. Precocious puberty may have long-term consequences including short stature later on in adulthood owing to premature epiphyseal fusion as also psychosocial problems. Evaluation includes a detailed history, physical examination, biochemical tests and imaging directed towards detecting the cause. Gonadotropin Releasing Hormone $(\mathrm{GnRH})$ analogues are effective for treatment of central precocious puberty. Treatment of peripheral precocious puberty should be based on the cause. Isolated variants are usually normal but should be closely monitored. Multi-speciality consultation with involvement of pediatricians and enocrinologists may improve treatment outcomes in these children, who otherwise pose significant challenges to the gynaecologist.
\end{abstract}

Keywords: Central precocious puberty, Gonadotropins, Precocious, Puberty, Peripheral precocious puberty, Precocious pubarche

\section{INTRODUCTION}

Adolescence is the period of life when a carefree child becomes a responsible adult. The term puberty and adolescence are commonly used inter-changeably. Puberty is the first stage of adolescence and the term tends to be used for the physical changes; the rest is the emotional and mental adaptation to sexual function. Puberty is a complex developmental process which begins in late childhood and is characterized by:

- maturation of hypothalamus-pituitary-gonadal axis [HPG]

- $\quad$ appearance of secondary sexual characteristics

- acceleration of growth

- capacity for fertility.
Premature sexual development or precocious puberty is defined as pubertal development occurring more than 2.5 standard deviations earlier than the average age. Traditionally, precocious puberty has been defined as appearance of secondary sexual characteristics before age of $8 \mathrm{yrs}$ in female and $9 \mathrm{yrs}$ in male. ${ }^{1}$ The overall incidence of sexual precocity is estimated to be 1:5000 to $1: 10,000$ with a female to male ratio of $10: 1 .^{2}$ Precocious puberty can affect children both physically and emotionally. A clear understanding of the physiology and timing of pubertal changes is important to manage precocious puberty.

This paper is an attempt to review the physiological alterations encountered during puberty in normal children 
and the mechanisms governing these alterations. There is a lack of agreement on the exact cutoff ages prior to which pubertal development may be considered abnormal. However, some recent articles in this regard will be reviewed. We will also discuss precocious puberty, with the focus on recent advancements in management and outcomes.

\section{PHYSIOLOGY OF NORMAL PUBERTY}

The onset of puberty is a sequence of various evolving maturational steps. The HPG axis develops and differentiates during fetal life with peak gonadotropin levels achieved at 24 weeks of gestation following which there is a steady decline till birth. After birth, the HPG axis escapes the suppressive effects of maternal and placental hormones and results in pulsatile secretion of GnRH which leads to increasing levels of gonadotropins and sex steroids. At around 3-6 months in males and 1218 months in females the high sensitivity of hypothalamus leads to negative feedback by the low circulating levels of gonadal steroids. Along with central inhibitory mechanisms, this suppresses the gonadotropins to prepubertal levels by 6-9 months in males and 24-36 months in females.

After a decade of quiescence, pulsatile secretion of GnRH resumes and the HPG axis is reactivated with resultant increase in levels of luteinizing hormone (LH) and follicle stimulating hormone (FSH) which leads to increased ovarian activity. Initially, the pulsatile secretions occur during night, more during sleep and then gradually extend through out the day. Increased ovarian follicular activity leads to increasing levels of estradiol which stimulates development of breast (thelarche). Adrenarche (adrenal androgen secretion) to unknown stimulus precedes gonadarche, begins by 6-8 yrs and continues till late puberty leading to growth of pubic and axillary hair (pubarche).

Pubertal growth spurt precedes thelarche and pubarche and is mediated by sex steroid induced increase in levels of groeth hormone $(\mathrm{GH})$ and insulin-like growth factor (IGF-1). At mid-puberty gonadal steroids reach sufficient levels to stimulate endometrial proliferation ultimately resulting in onset of menstruation (menarche). In general, the first sign of puberty in most adolescent girls is acceleration of growth, followed by thelarche, pubarche and finally menarche.

During early puberty, almost all assays for testosterone (in males) and estradiol (in females) have poor sensitivity and very high coefficients of variation owing to the extremely low concentrations of these hormones. This means that assessment of levels of these hormones during the onset of puberty may be unreliable. An association of several companies and organizations is attempting to take steps to improve the diagnosis efficacy of assays of these hormones.

\section{REGULATION OF NORMAL PUBERTY}

The neuroendocrine switch which is 'on' in early infancy, 'off' during childhood and again 'on' at puberty is regulated by various central and peripheral signalling pathways. The discovery of kisspeptin has increased the understanding of regulation of normal puberty. Kisspeptin secreting neurons in hypothalamus promote gonadotropin releasing hormone $(\mathrm{GnRH})$ secretion. Hypothalamic astrocytes and glial cells which are opposed to the GnRH neurons secrete growth factors which increase the growth and function of $\mathrm{GnRH}$ neurons. Increase in levels of this apposition increases GnRH secretion and the levels of apposition are negatively influenced by estradiol levels which may be the mechanism for the negative feedback of estradiol on gonadotropin levels. Activating mutation of genes for kisspeptin and its receptor have been found in individuals with precocious puberty. Peripheral signalling pathways involving leptin and ghrelin explain the role of a critical body weight composition to achieve puberty. Leptin stimulates the kisspeptin secretion whereas ghrelin suppresses its secretion. Each $1 \mathrm{ng} / \mathrm{ml}$ increase in leptin levels has been shown to reduce the age of menarche by 1 month.

As the overall age of pubertal development comes down, it is essential to differentiate otherwise normal children, maturing early from patients with pathologies, of which precocious puberty may be a manifestation. ${ }^{3}$ Hence, meticulous elicitation of history, a thorough physical assessment, evaluation of rate of physical maturation and hormonal assays are all required to be able to arrive at a diagnosis and direct management therefrom.

\section{TIMING OF PUBERTY}

The age of puberty is influenced by several factors like genetics, overall health, social environment and environmental exposures. Over the years, a declining trend in the age of onset of sexual development has been observed. Normal puberty refers to the time in which 95\% children attain initial pubertal signs (Tanner stage 2 of breast and pubic hair development). In the 1960s, cross-sectional data led to designation of the normal age range of pubertal onset between ages 8 and 13 years in girls and between ages 9 and 14 years in boys. ${ }^{1}$ This lasts for an average of 4.6yrs with passage from one stage to another by approximately every one year. Menarche occurs at an average of 2.6 years after onset of puberty. The average age of menarche in Indian adolescent girls is 12.6 years. $^{4}$

The timing of puberty is essential for any discussion on precocious puberty. It is a topic of much debate after the findings of two studies done in the 1990s, Paediatric Research in Office Settings study [PROS] and National Health and Nutrition Examination Survey data, which found earliest signs of puberty occurring at younger ages than in the past, with striking racial differences. Based on 
the findings of these studies, the paediatric endocrinology society revised their guidelines to reflect a normal age of puberty as 6 years in African-American girls and 7 years among white girls. ${ }^{5}$ These guidelines have not been accepted uniformly worldwide because of certain inherent flaws in the research methodologies and also fear of missing opportunities for diagnosing an abnormality earlier. The National Institute of Child Health and Human Development (NICHD)-sponsored Study of Early Child Care and Youth Development was undertaken in the year 1990 at 10 university centers in the United States. Girls in this study who were followed up annually from birth had average age at breast Tanner stage 2 of 9.9 years in whites and 9.1 years in African Americans. ${ }^{6}$ Larger prospective studies are needed to address this issue in context with evaluation of precocious puberty.

Why there should be differences in results between earlier trials and more contemporary ones is not very evident. There might exist significant differences in design of these studies, including involvement of different race/ethnicities, socioeconomic factors, definitions of what constitutes initiation of puberty, data collection, statistical analyses, and longitudinal/crosssectionsal evaluations. The global obesity pandemic over the last two decades might also be a contributing factor, with correlations between estimates of body fat and onset of puberty being noted, especially in girls. ${ }^{7-10}$

\section{CLINICAL STAGES OF PUBERTY}

The staging system used to describe the physical changes of puberty was first described by Marshall and Tanner in 1969-70. Tanner stages describe secondary sexual characteristics like breast development in girls, pubic hair growth in both sexes and genital development in boys (Table 1).

Table 1: Tanner staging of (a) Breast and (b) Pubic hair development.

\begin{tabular}{|l|ll|}
\hline Stage & $\begin{array}{l}\text { Breast } \\
\text { Prepubertal-elevation } \\
\text { of papilla }\end{array}$ & $\begin{array}{l}\text { Pubic hair } \\
\text { Preast budding - } \\
\text { elevation of breast and } \\
\text { papila hair }\end{array}$ \\
\hline II & $\begin{array}{l}\text { Sparse growth of long } \\
\text { mound. }\end{array}$ & $\begin{array}{l}\text { lightly pigmented hairs } \\
\text { on mons veneris /labia } \\
\text { majora }\end{array}$ \\
\hline III & $\begin{array}{l}\text { Continued } \\
\text { enlargement of breast } \\
\text { and areola without } \\
\text { separation of contours }\end{array}$ & $\begin{array}{l}\text { Additional darkening } \\
\text { and coarsening of } \\
\text { hair spreading over } \\
\text { pubic symphysis. }\end{array}$ \\
\hline IV & $\begin{array}{l}\text { Areola and nipple form } \\
\text { secondary mound } \\
\text { projecting above the } \\
\text { contour of breast }\end{array}$ & $\begin{array}{l}\text { Adult in character but } \\
\text { confined to the } \\
\text { suprapubic area }\end{array}$ \\
\hline V & $\begin{array}{l}\text { Adult shape, areola } \\
\text { and nipple recessed to } \\
\text { the contour of breast }\end{array}$ & $\begin{array}{l}\text { Adult in distribution } \\
\text { with spread to medial } \\
\text { thighs }\end{array}$ \\
\hline
\end{tabular}

\section{CLASSIFICATION OF PRECOCIOUS PUBERTY}

Traditionally precocious puberty has been classified according to the underlying pathophysiology into three types:

- Gonadotropin Dependent Precocious Puberty (True precocious puberty/central precocious puberty)

- Gonadotropin Independent Precocious Puberty (Pseudo-precocious puberty/peripheral precocious puberty)

- Incomplete Precocious Puberty (Premature thelarche, Premature adrenarche)

\section{Central precocious puberty (CPP)}

Central precocious puberty (CPP) is due to premature activation of the HPG axis. The sequence of pubertal development is maintained, and the sexual characteristics are isosexual (consistent with child's gender). The causes of CPP are primarly of central nervous system extraction, and are identical in both sexes, although idiopathic CPP occurs more often in females, with an incidence of around $90 \%$. Boys with a diagnosis of central precocious puberty, often have discrete causes. Children adopted internationally at an early age, have a higher incidence of CPP. The reason for this is unclear, but it is hypothesized that nutritional deprivation in early life followed by increased adiposity after adoption triggers the endocrine and physical changes of puberty earlier than would have otherwise occurred. ${ }^{11,12}$ Genetic and other environmental factors may also play roles.

\section{Peripheral precocious puberty (PPP)}

Peripheral precocious puberty (PPP) results due to exposure of sex steroid hormones derived from gonads, adrenals or environment. It may be isosexual or contrasexual (opposite to child's gender, e.g.: virilization in girls, feminisation in boys). Moreover, the causes may also be different between males and females, as opposed to CPP. Prolonged exposure to sex hormones from GnRH-independent etiologies could also however, result in conversion of peripheral to central precocious puberty, although the means through which these results are rather unclear. This usually results following withdrawal of exposure to the sex hormones, as might result following starting therapy in boys having simple virilizing congenital adrenal hyperplasia or termination of longterm exogenous administration of sex hormones.

\section{Incomplete precocious puberty}

Incomplete precocious puberty usually includes variants of normal pubertal development which sometimes may progress to complete precocious puberty. Premature thelarche refers to isolated development of breast which usually regresses over a period of time. Similarly, premature adrenarche is due to mildly elevated levels of androgens which leads to progressive development of 
pubic and axillary hair without breast development but may be associated with mildly advanced skeletal maturation. Premature thelarche demonstrates no additional features of puberty, like sudden growth spurt, rapid progression of development of mammary glands, or advancement of bone maturation. It is usually seen in toddler girls but occasionally in the older female child with isolated breast development. The significance of premature adrenarche, on the other hand, lies in the fact that, at least in some populations, it has been associated with increased cardiometabolic risk factors and an increased risk for polycystic ovary syndrome (PCOS) in later life. ${ }^{13,14}$

Table 2: Etiologies of precocious puberty.

\begin{tabular}{|c|c|}
\hline Precocious puberty & Etiologies \\
\hline Central precocious puberty & $\begin{array}{ll}\text { - } & \text { Idiopathic } \\
\text { - } & \text { CNS pathology/lesion } \\
\text { - } & \text { Hypothalamic hamartoma } \\
\text { - } & \text { Tumors (astrocytoma, glioma etc) } \\
\text { - } & \text { Congenital- hydrocephalus, arachnoid cysts, meningo-myelocele. } \\
\text { - } & \text { Acquired-CNS Irradiation, trauma, infection } \\
\text { - International adoption } \\
\text { - Secondary to peripheral precocious puberty }\end{array}$ \\
\hline Peripheral precocious puberty. & $\begin{array}{l}\text { - Ovarian causes -estrogen secreting tumors (granulosa cell tumor) androgen } \\
\text { secreting tumors (arrhenoblastoma, sertoli-leydig cell tumors) } \\
\text { - } \quad \text { Adrenal causes- adrenal tumors, Congenital adrenal hyperplasia, Cushings } \\
\text { syndrome } \\
\text { - McCune Albright syndrome (MAS) } \\
\text { - Longstanding hypothyroidism } \\
\text { - } \quad \text { Exogenous steroids- OCP's, anabolic steroids, facial creams }\end{array}$ \\
\hline Incomplete precocious puberty & $\begin{array}{l}\text { - } \quad \text { Premature thelarche } \\
\text { - } \quad \text { Premature adrenarche }\end{array}$ \\
\hline
\end{tabular}

Table 3: Evaluation of precocious puberty.

\begin{tabular}{|c|c|}
\hline History & $\begin{array}{l}\text { - Age of onset, sequence and progression of events } \\
\text { - Time of onset of puberty in mother and siblings } \\
\text { - } \quad \text { Past history of any neurological disease/trauma/infections } \\
\text { - Exposure to exogenous sex steroids in food, facial creams, drugs etc. } \\
\text { - Social history- child sexual abuse, international adoption }\end{array}$ \\
\hline Physical Examination & $\begin{array}{l}\text { - Height, Weight, Body mass index, growth velocity [cm/yr] } \\
\text { - Tanner staging of pubic hair and breast } \\
\text { - } \quad \text { Examination of skin-cafe au last spots [McCune Albright syndrome] } \\
\text { - } \quad \text { Abdominal examination- any palpable abdominal mass } \\
\text { - } \quad \text { Neurological examination } \\
\text { - } \quad \text { Signs of virilisation - hirsutism, clitoromegaly, deepening of voice. }\end{array}$ \\
\hline Biochemical investigations & $\begin{array}{l}\text { - } \text { Basal gonadotropin (LH, FSH) levels. } \\
\text { - } \text { EnRH stimulation tests } \\
\text { - } \quad \text { Adrenal steroids- DHEA-S, 17OH -progesterone, androstenedione } \\
\text { - } \quad \text { (raised in adrenal tumors, congenital adrenal hyperplasia) } \\
\text { - } \quad \text { ACTH stimulation tests - congenital adrenal hyperplasia } \\
\text { - } \quad \text { Free thyroxine and TSH levels - Hypothyroidism } \\
\text { - } \quad \text { Serum Prolactin-raised in prolactinoma, hypothyroidism }\end{array}$ \\
\hline Imaging & $\begin{array}{l}\text { - Xray of left wrist for bone age } \\
\text { - } \text { CT /MRI brain } \\
\text { - CT adrenals. } \\
\text { - } \quad \text { Pelvic ultrasound-shape, size of uterus, endometrial thickness, ovarian morphology }\end{array}$ \\
\hline
\end{tabular}


Another form of incomplete precocious puberty, "premature menarche" is also known to occur, but the syndrome lacks clarity with regard to definition and the pathophysiologic mechanisms underlying it are therefore not very well researched. ${ }^{15}$

The causes of various types of precocious puberty are depicted in Table 2.

\section{EVALUATION OF PRECOCIOUS PUBERTY}

The initial evaluation of early sexual development begins with a detailed history and physical examination along with measurement of bone age to see if there is any advanced bone age in comparison with the chronological age.

Children with advanced bone age and those having normal bone age with breast and pubic hair development or normal bone age with evidence of growth acceleration and breast or pubic hair development should be subsequently evaluated with the intent of finding the pathology behind the premature sexual development (Table 3).

When pathological precocious puberty is the evident diagnosis, the logical clinical sequel is to investigate whether it is GnRH dependent or independent. Boys suspected to be having CPP would generally have symmetrically enlarged testicular volumes, while with PPP testes that are typically prepubertal or extremely small compared to the amount of virilizing signs these children demonstrate.

Uncommon pathologies in these children may be bilateral testicular Leydig cell or adrenal rest tumors. In girls however, a pelvic ultrasonography to quantify ovarian volume may not be able to diagnose the type of precocious puberty, although it might serve as an adjunct to other investigations. ${ }^{16}$

\section{HORMONAL AND IMAGING PROFILE}

The gold standard for diagnosis of CPP is GnRH stimulation test where the LH levels are measured 15-60 min after GnRH stimulation/GnRH analogue administration. A prepubertal LH pulse reaches 1.5-2.0 U/L whereas a level greater than 4-5 U/L suggests that puberty has begun. Unstimulated prepubertal levels of LH is usually less than $0.1 \mathrm{U} / \mathrm{L}$.

Ultra-sensitive assays which can test for random baseline LH can be used for checking activation of HPG axis. Various cut-offs ranging from 0.1-1.5 U/L show different sensitivity and specificity. Basal FSH or GnRH stimulated FSH levels are not helpful in differentiating children with or without precocious puberty. However, a GnRH stimulated peak LH/FSH ratio of $0.6-1.0$ has been suggested for diagnosis of precocious puberty. ${ }^{5}$ The hormone profile for evaluating precocious puberty is described in Table 3.

Once elevated basal and stimulated levels of LH indicate central precocious puberty, imaging of head (Magnetic Resonance Imaging / Computerized Tomography) should be done to rule out any central nervous system (CNS) pathology. Ultrasound of abdomen and pelvis should be directed towards detecting adrenal tumors, ovarian cysts / ovarian volume (it is usually less than $1 \mathrm{cc}$ in prepubertal age) or endometrial stripe. X-Ray of left wrist should be done for bone age. Bone age is usually advanced by 2 yrs or more, normal bone age with clinical features of precocious puberty should not dissuade one from further assessment.

\section{MANAGEMENT OF PRECOCIOUS PUBERTY}

\section{Central precocious puberty}

The mainstay of treatment for CPP is GnRH analogues. GnRH analogues cause desensitisation and downregulation of GnRH receptors leading to reduced secretion of gonadotropins. Different preparations and routes of administration are used in various countries. In the United States, depot Leuprolide acetate and Histrelin implants are commonly used, whereas depot triptorelin is widely used in Europe. They cause regression or stabilization of the pubertal changes, reduce the growth velocity to prepubertal levels and stop the advancement of bone age. There are no standard protocols for monitoring.

The GnRH stimulation test after administration of short acting GnRH or estimation of LH levels after 30-60 min of giving depot GnRHa can be used to monitor therapy. Levels of LH obtained should not cross the prepubertal value of 4-5 U/L. Usually monitoring is done in the first year of treatment. Treatment can continue till pubertal and chronological ages are appropriately matched or until the epiphyses have fused. It is usually interrupted by $10-$ $11 \mathrm{yrs}$, so that they get menarche around population norms.

\section{OUTCOMES OF GnRHA TREATMENT}

\section{Height}

Height gain achieved with GnRHa is the difference between final height and pre-treatment predicted adult height. As much as $9.8 \mathrm{~cm}$ gain in height has been reported in trials. Greatest increase in height has been obtained in girls treated at less than 6 years of age.

\section{Bone health and composition}

During treatment with GnRHa there may be stable or slight reduction in bone mass but subsequently bone mass accrual is normal and peak bone mass is not negatively affected by GnRHa. 


\section{Pyscho-social effects}

None of the studies have shown that intervention with GnRHa improves the behavioral problems associated with precocious puberty.

\section{Reproductive function}

Levels of estradiol and pulsatility of gonadotropins return to normal after discontinuation of GnRHa treatment. Menses usually occur by 9-20 months after stopping the treatment. Studies have reported no difficulty in conception or any adverse pregnancy outcomes in the treated patients. Whether treated patients develop hyperandrogenism and PCOS later on is still not adequately established.

\section{Peripheral precocious puberty}

Treatment of precocious puberty is directed to the underlying cause.

Treatment of McCune-Albright syndrome (MAS) is challenging. It is characterized by polyostotic fibrous dysplasia, cafe au lait spots in skin and precocious puberty. Treatment has been directed towards aromatase inhibition and oestrogen receptor blockade. Most of these agents are ineffective and cause increase in uterine or ovarian size. Third generation aromatase inhibitor letrozole and a pure oestrogen receptor blocker (fulvestrant) have shown promising results by reducing the number of bleeding episodes and rate of bone maturation. ${ }^{17}$

\section{Incomplete precocious puberty}

Isolated premature thelarche or adrenarche usually do not require any treatment as they may be normal variants of early pubertal growth. However, they should be closely followed up as a few of them may develop complete precocious puberty and need to be evaluated further and managed.

\section{CONCLUSION}

Precocious puberty continues to be an enigma being slowly unravelled by the discovery of the regulators of puberty like kisspeptin which may throw more light on this clinical condition. Investigations should be directed to differentiate central and peripheral causes from the common variants. GnRH therapy is well tolerated and a highly effective treatment for CPP. More research is required to evaluate the long term outcomes after $\mathrm{GnRH}$ treatment as well as to formulate therapeutic strategies for MAS on which to establish clinical guidelines.

\section{Funding: No funding sources}

Conflict of interest: None declared

Ethical approval: Not required

\section{REFERENCES}

1. Latronico AC, Brito VN, Carel JC. Causes, diagnosis, and treatment of central precocious puberty. Lancet Diabetes Endocrinol. 2016;4:265274.

2. Tirumuru SS, Arya P, Latthe P. Understanding precocious puberty in girls. Obstetrician Gynaecologist. 2012;14:121-9.

3. Sorensen K, Mouritsen A, Aksglaede L, Hagen CP, Mogensen SS, Juul A. Recent secular trends in pubertal timing: implications for evaluation and diagnosis of precocious puberty. Horm Res Pediatr. 2012;77:137-45.

4. Fritz MA, Speroff L. Clinical gynecologic endocrinology and infertility. In: Normal and abnormal growth and pubertal development, 8th edn. Lippincott Williams and Wilkins, Philadelphia;2010:391-433.

5. Neely EK, Crossen SS. Precocious puberty. Curr Opin Obstet Gynecol. 2014;26:332-8.

6. Susman EJ, Houts RM, Steinberg L, Belsky J, Cauffman E, DeHart Get al. Longitudinal development of secondary sexual characteristics in girls and boys between ages 9 1/2 and 15 1/2 years. Arch Pediatr Adolesc Med. 2010;164:166-73.

7. Herman-Giddens ME, Steffes J, Harris D, Slora E, Hussey M, Dowshen SA et al. Secondary sexual characteristics in boys: data from the Pediatric Research in Office Settings Network. Pediatrics. 2012;130: e1058-e1068.

8. Biro FM, Khoury P, Morrison JA. Influence of obesity on timing of puberty. Int $\mathbf{J}$ Androl. 2006;29:272-7.

9. Kaplowitz PB, Slora EJ, Wasserman RC, Pedlow SE, Herman-Giddens ME. Earlier onset of puberty in girls: relation to increased body mass index and race. Pediatrics. 2001;108:347-53.

10. Rosenfield RL, Lipton RB, Drum ML. Thelarche, pubarche, and menarche attainment in children with normal and elevated body mass index. Pediatrics. 2009;123:84-8.

11. Soriano-Guillen L, Corripio R, Labarta JI, Cañete R, Castro-Feijóo L, et al. Central precocious puberty in children living in Spain: incidence, prevalence, and influence of adoption and immigration. J Clin Endocrinol Metab. 2010;95:4305-13.

12. Teilmann G, Pedersen CB, Skakkebaek NE, Jensen TK. Increased risk of precocious puberty in internationally adopted children in Denmark. Pediatrics. 2006;118:e391-e399.

13. Ibanez L, Diaz R, Lopez-Bermejo A, Marcos MV. Clinical spectrum of premature pubarche: links to metabolic syndrome and ovarian hyperandrogenism. Rev Endocr Metab Disord. 2009;10:63-76.

14. Vuguin P, Grinstein G, Freeman K, Saenger P, DiMartino Nardi J. Prediction models for insulin resistance in girls with premature adrenarche. The premature adrenarche insulin resistance score: PAIR score. Horm Res. 2006;65:185-91. 
15. Saggese G, Ghirri P, Del Vecchio A, Papini A, Pardi D. Gonadotropin pulsatile secretion in girls with premature menarche. Horm Res. 1990;33:5-10.

16. Sathasivam A, Rosenberg HK, Shapiro S, Wang H, Rapaport R. Pelvic ultrasonography in the evaluation of central precocious puberty: comparison with leuprolide stimulation test. J Pediatr. 2011;159:4905.
17. Fuqua JS. Treatment and outcomes of precocious puberty. J Clin Endocrine Metab. 2013;98:2198-207.

Cite this article as: Pallavee P, Samal R. Precocious puberty: a clinical review. Int J Reprod Contracept Obstet Gynecol 2018;7:771-7. 